\title{
The Effect of Group Cooperative Learning on Improving English Language Output Ability
}

\author{
Li Zhu \\ Zaozhuang University, Zaozhuang Shandong, 277160, China
}

Key words: English language output ability, Group cooperative learning, Meaning.

\begin{abstract}
In recent years, the current situation of each subject and subject teaching in our country has played a positive role in improving students' cooperation and mutual assistance, cultivating independent innovation and improving comprehensive literacy. Group cooperative learning is an indispensable form of college English teaching, in improving students' language output ability to play a positive significance.
\end{abstract}

\section{Introduction}

With the vigorous implementation of the new curriculum reform in our country, the college English classroom has gradually changed from "teacher-oriented" to "student-oriented", highlighting the student's dominant position. English is the carrier of language and culture, the ultimate goal of English language learning is communication [1]. Since the 21st century, with the rise of China's international status, the economic strength of the increase, more and more foreign enterprises choose to enter the Chinese mainland investment and development, social and business needs of integrated English talents and requirements to another height. In order to further deepen the teaching reform and enhance the students' English proficiency, the major teaching methods are introduced into the actual teaching classroom, among which the group cooperative learning is the most prominent. Group cooperation to learn innovative and flexible [2], can fully stimulate the enthusiasm and initiative of students, to achieve independent and personalized learning objectives, to enhance students' language output ability has a positive meaning.

\section{Definition and Theory of Group Cooperative Learning}

Group to learn to learn the group as the basis, to maximize the group to play their own active function to mobilize the collective power of individual learning initiative to achieve win-win cooperation goals. Compared with the traditional teaching model, the group cooperative learning has changed the monopoly situation of the teacher-led classroom, so that students return to the active state of learning, have more time and space for personalized development, and access to a wider interpersonal And the scope of social function, to enhance its ability to use language has a positive practical significance. In addition, the group cooperative learning construction in the "group homogeneity, group heterogeneity" principle [3], emphasizing respect for student learning and growth differences and individuality, concentrated in the learning base, personality, gender, learning ability and Psychological characteristics and other aspects, that is, "group heterogeneity", teachers in practice to do the perfect combination of excellent and poor, so that the maximum mobilization of each student's own strengths and characteristics, and from others to learn experience and knowledge To avoid weaknesses, to enhance the level and ability of individuals. Teachers set up group learning activities, so that each group of students to learn together to collectively affect the initiative to mobilize the 
enthusiasm of individual learning, so that the overall capacity of the team members tend to basically the same state, which is "between groups of homogeneity."

\section{The Significance of Group Cooperative Learning in College English Teaching}

The reason why the university is big, lies in its "freedom" and "tolerance", the group cooperative learning activities and this idea is exactly the same. Generally speaking, the university stage is the key period of the individualization and autonomy of the students, and has some influence on its future employment and lifelong development. Group cooperative learning refers to the organization and guidance of teachers, according to the "excellent difference" combination of the principle of grouping of students, and lead to specific topics for students to exchange cooperation between groups. Specifically, the group cooperative learning in college English teaching is as follows:

\section{Help to eliminate the anxiety of language learning}

English is the second foreign language of the vast majority of Chinese students. Students can show different degrees of anxiety, fear or shyness, such as language thinking, cultural differences, learning environment and other factors [4]. Cooperate with groups to carry out teaching activities, students are no longer independent individuals, but a member of the group. Through mutual cooperation and exchanges, to create a relaxed, pleasant classroom atmosphere, students gradually form a collective concept, mutual help, learn from each other. Group strength can enhance individual self-confidence, the language of learning fear and anxious sense of corresponding decline.

\section{Help to cultivate learning independence and autonomy}

English is an important tool for communication and communication. In view of this, college English teaching should be based on the promotion of students 'English culture level, and constantly train students' English critical thinking, and guide students to learn to think in English. Group cooperative learning activities is an effective way [5]. In the group of cooperative learning, each member can freely express their own views, in the study of the formation of personal thinking, comprehensive exercise of their language, thinking innovation and courage. In addition, under the influence of a long time, mutual learning on their own or others can have a subtle influence, through continuous summary and reflection, students can form a unique individual and has a personalized mode of thinking, the English expression and output ability can also be corresponding improve.

\section{Help to cultivate language expression and communication skills}

Group cooperation to learn more prominent members of the group collaboration and interaction, only to strengthen the division of labor between the cooperation, the group can really complete the learning task. Group members are similar in age, but their knowledge level and understanding ability may be different, different students in college English learning can show different behavioral mechanism and development characteristics [6]. Therefore, students in the learning process can have a certain degree of difference and individuality, and under the action of the group activities, students can experience different views of the friction, integration and improvement process, in the consultation and discussion process to exercise their own language expression and Communication skills.

\section{Help to improve students' language output}

The group learning activities emphasize students' subjective position. Teachers can provide students with dialogue, questioning, role play or discussion on specific topics or topics, and provide opportunities for students to participate in language discussion and communication in many ways, so that students can feel in the real language environment, Test and summarize language use. The ultimate goal of language learning is for communication, is the output, and thus teaching activities should maximize the students to provide real opportunities for communication, so that students really feel the meaning and value of language communication, and actively participate in or seek 
extracurricular exercise opportunities, to strengthen the English language to write, say a lot of language output ability to exercise.

\section{Practice of Group Cooperative Learning in College English Teaching}

\section{The Group Cooperates to Study the Background of College English Teaching}

Since the deepening of the development of opening up, China's exchanges with countries around the world continue to increase. Cultural background, the foreign language has become the link between China and the exchange of communication [7]. With the deepening of teaching reform, China's college English teaching has made great progress and remarkable results for the community and enterprises to train a number of high-level, high-quality comprehensive English talents. In recent years, social progress, rapid economic development of English talent requirements are getting higher and higher, so the corresponding requirements of education and teaching to put forward more specific and specific training objectives. However, from the overall situation of college English teaching in China, time-consuming, low efficiency and other disadvantages become increasingly prominent. From the teaching level, some teachers still follow the old educational thinking, the classroom most of the time for vocabulary, grammar and other basic knowledge to explain, weighing the University of four or six, four professional and eight examinations, do not pay attention to cultivate student language output And the practical use of the ability. From the learning level, some students did not form a unique mode of thinking, it is difficult to jump out of the examination of the cage, that English learning is to meet the various examinations and professional certificate to receive, will take the certificate as a future stepping stone, do not pay attention to the development of their own The actual use of language skills. In view of this, college English teaching needs further reform and deepening. In the era of information sharing, college English teaching usher in the teaching of large data changes, to strengthen students' self-learning, mutual cooperation become the inevitable trend of teaching reform.

\section{Practice of Group Cooperative Learning in College English Teaching}

School education and teaching is the interaction between teachers and students, life and life and life behavior, are students understand the world, understand the window of things. However, there are essential differences and differences in school education at different stages. Compared with junior high school teaching, university teaching is more "free" and "tolerant", which means that university is the student's individuality and independence. Critical period [8]. College English teachers should make full use of this feature, in the classroom teaching flexible into the group of cooperative learning, independent individuals into the group cooperation, in order to achieve complementary advantages, mutual help each other teaching objectives. Group cooperative learning in college English teaching practice as follows:

\section{Reasonable, scientific configuration team members}

Each student is an independent individual, its English learning ability, knowledge level, personality and preferences and so there are some differences and individuality, but also determines its personal growth and development direction. Language output ability is an important indicator to evaluate individual language ability. Personal output ability has certain relation with its character and preference, but most depends on knowledge reserve and flexible coping ability. In other words, the student language output ability and the accumulation of the day after day is more closely. While the student group age similar to its physical and mental development although there is a certain regularity, but individuals can show the individual trend in the general trend. Thus, arranging different students to the same group can help to achieve complementary advantages and interoperability goals. Teachers can be based on "group homogeneity, group heterogeneity" principle of scientific team members, in the group may be appropriate to allocate English language output ability is high, good foundation students, and then arrange the basis of weak, not good at language expression students, So 
that it can facilitate future activities and teaching to carry out. This group of forms of targeted, can fully respect the characteristics of the development of individual students, but also from the overall performance of students to meet the needs of mutual support.

\section{Clear the language output ability to develop specific programs}

English learning is mainly focused on Listening, Speaking, Writing and Reading four aspects, the school teaching is to enhance students to listen, read, write skills on important goals. "Speaking and writing" belongs to the language output category, for this to strengthen the students "listening" and "writing" exercise is an important way to enhance the language output ability. Traditional university teaching is mainly based on the theory and basic knowledge teaching, spend a lot of time pro forma examination, certificate examination, too much emphasis on the examination results lead to a considerable part of the university graduates in the actual job can not say, do not understand, The useless furnishings. Therefore, college English teachers should see this serious situation, according to the growth characteristics of students and English learning situation clear and specific teaching programs to guide students from reading, listening and other aspects of knowledge reserves, and good at its flexibility to apply to Speak and write, learn to use, to enhance students' language output ability.

\section{Organize diversified teaching activities}

After clarifying the teaching objectives, teachers can organize their learning activities according to the specific teaching contents, and do a good job of students' oral communication and writing. Oral communication is a major way of language output, teachers should actively create a certain language communication environment, the text into the form of oral communication, so that students into the role to experience, exercise and promotion. Writing expression is also a major way of language output, through the writing can be found in their own language errors, knowledge loopholes, timely leaks, and can improve the English thinking ability (Critical thinking), dare to question and put forward their own views, The formation of the original English thinking mode. In particular, teachers can introduce English speeches, storytelling, debates, interpreters, and theater performances on a subject or topic, as well as writing, translating, and so on, so that students can continue to participate in the process of participation Its own language organization, language expression and language skills to enhance its language output capacity.

\section{Strengthen the free exchange and collaboration of team members}

Group members are small members of the group, in the daily learning activities in the mutual help, strengthen exchanges and collaboration. Language output, especially spoken English, is not a quick act, but a cumulative behavior. Therefore, the cultivation of language proficiency is the accumulation and practice of living and learning, and should be carried out throughout the teaching and learning activities [9]. Classroom teaching, teachers should be more text content into a dialogue form of dialogue, so that students two or more people between the dialogue simulation exercises, on the one hand can mobilize the classroom atmosphere, so that students participate in classroom exchange activities; the other hand, Increase the chance of English language communication, timely correct the language errors of students, add language skills, so that students say more, more practice, and more use, to enhance their language expression and ability to use. In addition, teachers can organize writing or translation activities in the classroom, allowing students to discuss, strengthen collaboration and interaction, divergent thinking.

\section{Conclusions}

In short, the group cooperative learning is an important teaching form of college English teaching, but also a powerful way to enhance students' English language output ability. The ultimate goal of English learning is to communicate with each other. Therefore, teachers should actively create more opportunities in daily teaching so that students can perceive the importance of English language 
communication in practice and gradually form speculative ability and enhance their ability to express language.

\section{Acknowledgement}

This paper is supported by the Zaozhuang College School-level Teaching Reform Project YJG15025.

\section{References}

[1] Tu Xianfang. Practice and Reflection on the Mode of "Cooperative Group" in College English Teaching, Campus English, 2015（28）:84.

[2] Wang Yuanyuan. The Application of Group Cooperation Model in College English Translation Teaching, Science and Technology (Late),2015 (04):119-120.

[3] Lu Shuling. The Problems and Countermeasures in the Cooperative Study of College English Group, Shan Hai Jing, 2015 (24）:67.

[4] Luo Yan. Exploration and Practice of College English Culture Teaching under the Mode of Group Cooperative Learning, Technology perspective, 2016 (26):186.

[5] Yu Xiuhua. The Application of Group Cooperative Learning in College English Teaching, Journal of Ezhou University, 2015,23（05）:71.

[6] Huang Yawen. The Application of Group Cooperative Learning in College English Classroom, Academic research, 2015 (24):225.

[7] Lin Lin. On the Role of Group Cooperative Learning in College English Teaching, Encouragement, 2016 (09) :94.

[8] Zhao Huifang. On the Gains and Losses of Group Cooperative Learning in English Teaching, Development guide, 2017 (08) :1-2.

[9] Yao Lifen. A Study of Group Cooperative Learning to Improve English Language Output Ability, New course study, 2013 (18):50. 